\title{
Incidence of retinopathy of prematurity in New Zealand
}

\author{
B A DARLOW
}

Department of Paediatrics, Christchurch School of Medicine, Christchurch, New Zealand

SUMMARY The incidence of retinopathy of prematurity has been prospectively assessed in very low birthweight infants born in one year in New Zealand. A total of $26(11 \%)$ surviving infants with birth weight $1000-1499 \mathrm{~g}$ had acute retinopathy. Forty one $(49 \%)$ surviving infants with birth weight $500-999 \mathrm{~g}$ had acute retinopathy and of these six (7\%) became bilaterally totally blind.

It is clear that the incidence of retinopathy of prematurity has been increasing from the early 1970 s, apparently largely as a consequence of enhanced survival of very low birthweight infants (birth weight less than $1500 \mathrm{~g}$ ) resulting from modern advances in neonatal intensive care. ${ }^{1}$ While there have been several reports of the prevalence of retinopathy of prematurity in individual institutions and rather fewer cooperative studies involving several institutions, there have been very few regional or population based studies. In New Zealand there was no information on the annual incidence of acute retinopathy of prematurity or even blindness caused by it. There has, however, been considerable debate as to how far the disorder might be preventable and whether infants suffering from severe retinopathy of prematurity might qualify for compensation from the Accident Compensation Commission.

The aims of the present study were to document all cases of retinopathy of prematurity occurring in very low birthweight infants born in New Zealand in 1986 and to prospectively record data comprising 180 items relating to perinatal and neonatal events. The preliminary results for the national incidence of acute retinopathy of prematurity and early severe visual impairment due to retinopathy of prematurity are reported.

\section{Methods}

Considerable planning was undertaken before starting the study on 1 January 1986: this involved discussions with neonatologists and paediatricians in all level III neonatal centres (five) and level II centres (17) in New Zealand. For every infant with a birth weight of less than $1500 \mathrm{~g}$ a standard record sheet was completed with details of maternal and birth history and neonatal course. All infants who survived long enough were to have indirect ophthalmoscopy initially at 6 to 9 weeks of age by an ophthalmologist skilled in the technique. The protocol was fully discussed with ophthalmologists in the main centres before the study and a paper on examination technique, with emphasis on the need for adequate mydriasis and scleral indentation, circulated by a senior ophthalmological colleague in Christchurch . ${ }^{2}$ Findings at indirect ophthalmoscopy were reported using the International Classification of Retinopathy of Prematurity. ${ }^{3}$ If abnormalities were detected at the initial examination the infant was to have further review. If for any reason an infant did not have ophthalmic review at the appropriate time, late review was encouraged.

The study received approval from the ethical committee of the Canterbury Hospital Board and the support of the executive of the Paediatric Society of New Zealand.

\section{Results}

There were 411 infants with a birth weight 500-1499 $\mathrm{g}$ admitted to neonatal units throughout New Zealand in 1986. Seventy four infants died before discharge home giving a survival of $82 \%$.

Of 279 liveborn infants with a birth weight 1000-1499 g, 29 died giving a survival to discharge home of $90 \%$. Of 132 liveborn infants with a birth weight 500-999 g, 45 died giving a survival to discharge home of $66 \%$.

Three hundred and thirteen (93\%) of the 337 surviving infants with birth weight 500-1499 $\mathrm{g}$ had examination by indirect ophthalmoscopy. Two hundred and twenty nine (92\%) of the 250 surviving infants with birth weight $1000-1499 \mathrm{~g}$ and $84(97 \%)$ of the 87 surviving infants with birth weight $500-999 \mathrm{~g}$ were examined.

One hundred and forty one infants (45\%) had indirect ophthalmoscopy from six to nine weeks after birth; $88(62 \%)$ of this group had at least two examinations. In 68 infants $(22 \%)$ a single examination was carried out at 5 weeks of age or earlier but in 24 of these infants this examination was at 35 weeks or more from conception. In 104 infants $(33 \%)$ the first examination was at 10 weeks of age or more but in 36 of these infants this examination was earlier than 42 weeks' postconception. Thus 201 
infants $(64 \%)$ had an examination at a time most optimal to detect acute retinopathy of prematurity. Additionally in $10 \%$ of examinations it was recorded that one or other retina had not been fully seen, usually the extreme temporal periphery.

Sixty seven $(21 \%)$ infants with birth weight 500-1499 g who had an ophthalmic review had acute retinopathy of prematurity and six $(2 \%)$ became bilaterally totally blind. Twenty six $(11 \%)$ infants with birth weight 1000-1499 g who had an ophthalmic review had acute retinopathy of prematurity. Forty one (49\%) infants with birth weight $500-999 \mathrm{~g}$ who had an ophthalmic review had acute retino- pathy of prematurity and six ( $7 \%$ ) became bilaterally totally blind.

Changes of acute retinopathy of prematurity were observed in $29(64 \%)$ of the 45 infants with gestation of 24-26 weeks, $31(21 \%)$ of the 140 infants with gestation of 27 to 29 weeks, and seven $(6 \%)$ of the 128 infants with gestation of 30 weeks or more.

Details of the stage of retinopathy of prematurity $\%$ and gestational age and birth weight are given in $\vec{\circ}$ tables 1 and 2 . Nearly three quarters of the infants with a birth weight less than $1000 \mathrm{~g}$ with retinopathy $\vec{\omega}$ of prematurity had mild stage 1 or 2 disease and only one surviving infant with birth weight $1000-1499 \mathrm{~g}$

Table 1 Retinopathy of prematurity in very low birthweight infants in New Zealand in 1986 and gestation

\begin{tabular}{|c|c|c|c|c|c|c|c|c|c|}
\hline \multirow{2}{*}{$\begin{array}{l}\text { Gestation } \\
\text { (weeks) }\end{array}$} & \multirow{2}{*}{$\begin{array}{l}\text { No } \\
\text { of } \\
\text { infants }\end{array}$} & \multirow{2}{*}{$\begin{array}{l}\text { No }(\%) \text { of } \\
\text { survivors }\end{array}$} & \multirow{2}{*}{$\begin{array}{l}\text { No of infants } \\
\text { having } \\
\text { ophthalmic } \\
\text { examination }\end{array}$} & \multicolumn{4}{|c|}{ Retinopathy of prematurity stage* } & \multirow{2}{*}{$\begin{array}{l}\text { Total No } \\
\text { (\%) with } \\
\text { retinopathy of } \\
\text { prematurity }\end{array}$} & \multirow{2}{*}{$\begin{array}{l}\text { No } \\
(\%) \\
\text { blind }\end{array}$} \\
\hline & & & & 1 & 2 & 3 & 4 & & \\
\hline 24 & 9 & 2 (22) & 2 & 1 & 1 & - & - & $2(100)$ & - \\
\hline 25 & 27 & 16 (59) & 16 & 5 & 5 & - & 3 & $13(81)$ & $3(19)$ \\
\hline 26 & 43 & 28 (65) & 27 & 2 & $6+$ & 4 & 2 & 14 (52) & $2(7)$ \\
\hline 27 & 47 & 36 (77) & 35 & 8 & $3 t$ & 1 & 1 & 13 (37) & 1 (3) \\
\hline 28 & 63 & 47 (75) & 44 & 7 & 2 & $-\dagger$ & - & $9(20)$ & - \\
\hline 29 & 71 & $65 \quad(92)$ & 61 & 3 & 6 & - & - & 9 (15) & - \\
\hline 30 & 60 & 54 (90) & 51 & 2 & 0 & 1 & - & $3 \quad(6)$ & - \\
\hline 31 & 31 & 30 (97) & 28 & 2 & 1 & - & - & 3 (11) & - \\
\hline 32 & 25 & 24 (96) & 22 & 1 & - & - & - & 1 (5) & - \\
\hline $33-38$ & 35 & $35(100)$ & 27 & 0 & 一 & - & - & - & - \\
\hline Total & 411 & $337(82)$ & 313 & 31 & 24 & 6 & 6 & $67 \quad(21)$ & 6 (2) \\
\hline
\end{tabular}

*If asymmetrical disease was present the stage in the most severely affected eye is shown.

†Further case found in infant who died postneonatally.

Table 2 Retinopathy of prematurity in very low birthweight infants in New Zealand in 1986 and birth weight

\begin{tabular}{|c|c|c|c|c|c|c|c|c|}
\hline \multirow{2}{*}{$\begin{array}{l}\text { Birth weight } \\
(g)\end{array}$} & \multirow{2}{*}{$\begin{array}{l}\text { No of } \\
\text { infants }\end{array}$} & \multirow{2}{*}{$\begin{array}{l}\text { No }(\%) \text { of } \\
\text { survivors }\end{array}$} & \multirow{2}{*}{$\begin{array}{l}\text { No of infants } \\
\text { having ophthalmic } \\
\text { examination }\end{array}$} & \multicolumn{4}{|c|}{ Retinopathy of prematurity stage* } & \multirow{2}{*}{$\begin{array}{l}\text { Total No (\%) } \\
\text { with retinopathy } \\
\text { of prematurity }\end{array}$} \\
\hline & & & & $I$ & 2 & 3 & 4 & \\
\hline \multicolumn{9}{|c|}{ Infants weighing $500-999 \mathrm{~g}$} \\
\hline $500-599$ & 3 & $2(60)$ & 2 & 1 & 1 & - & - & $2(100)$ \\
\hline $600-699$ & 18 & $10(56)$ & 10 & 1 & 1 & - & 2 & $4(40)$ \\
\hline 700-799 & 33 & $22(67)$ & 22 & 4 & 6 & 1 & - & $11(50)$ \\
\hline $800-899$ & 35 & $22(63)$ & 21 & 4 & $4 \dagger$ & 2 & 2 & $12(57)$ \\
\hline $900-999$ & 43 & $31(72)$ & 29 & 4 & 4 & 2 & 2 & $12(41)$ \\
\hline \multirow[t]{2}{*}{ Total } & 132 & $87(66)$ & 84 & 14 & 16 & 5 & 6 & 41 (49) \\
\hline & \multicolumn{7}{|c|}{ Infants weighing $1000-1499 \mathrm{~g}$} & \multirow{6}{*}{$\begin{array}{rr}11 & (26) \\
6 & (13) \\
3 & (9) \\
4 & (8) \\
2 & (3)\end{array}$} \\
\hline 1000-1099 & 54 & $44(81)$ & 42 & 8 & $2 \dagger$ & 1 & - & \\
\hline $1100-1199$ & 56 & $46(82)$ & 45 & 6 & - & $-\dagger$ & - & \\
\hline $1200-1299$ & 43 & $38(88)$ & 35 & 1 & 2 & - & - & \\
\hline $1300-1399$ & 60 & $58(97)$ & 49 & 1 & 3 & - & - & \\
\hline $1400-1499$ & 66 & $64(97)$ & 58 & 1 & 1 & - & - & \\
\hline Total & 279 & $250(90)$ & 229 & 17 & 8 & 1 & - & $26(11)$ \\
\hline
\end{tabular}

*If asymmetrical disease was present the stage in the most severely affected eye is shown.

†Further case found in infant who died postneonatally. 
had proliferative retinopathy of prematurity (stage 3 or more). Only one surviving infant of 28 weeks' gestation or more with retinopathy of prematurity had other than mild stage 1 or 2 disease.

Additionally seven infants who died postneonatally had an ophthalmic review, and three had acute retinopathy of prematurity.

\section{Discussion}

Several authors have emphasised the need for population based studies of the incidence of retinopathy of prematurity as a preliminary to a better understanding of the aetiology, prevention, and treatment of this disorder. ${ }^{14}$ Good prospective follow up of children who have required intensive care is, or should be, an integral part of a newborn intensive care service. Parents and care givers need to know about problems and potential handicaps at an early stage. Knowledge of the incidence of a disorder such as retinopathy of prematurity and whether it is increasing or not, not only facilitates critical review of standards of care but also means that there can be national planning for the future care of children with severe visual handicaps.

Flynn and others have highlighted the fact, also apparent from earlier literature, that if retinal examination is too soon after birth acute retinopathy of prematurity may be missed as changes often develop later in more premature infants. ${ }^{5}$ Equally if the examination is too late any acute changes may have regressed and no sequelae be detected. This may account for the wide variation in the reported incidence of acute retinopathy of prematurity. ${ }^{1}$

The main reasons for one third of the infants not having an ophthalmic review at a time most optimal to detect acute retinopathy of prematurity in the present study were that the smallest infants were often too sick for examination to be attempted; that more mature infants were either examined early before transfer to a smaller centre nearer home or had to return to the main centre for examination at a later date; and lastly that some infants failed to attend repeat appointments. Together with the fact that in $10 \%$ of examinations the retina, albeit usually the extreme temporal periphery, could not be fully visualised, these factors may contribute to the relatively low incidence of acute retinopathy of prematurity seen in this study compared with some unit based studies in which repeat examinations were carried out until full vascularisation of the retina. ${ }^{5}$ On the other hand the proportion of more mature, growth retarded infants in this population based study is likely to be greater than in studies from specialised referral units.

All six infants with stage 4 retinopathy of pre- maturity were considered to have developed bilateral complete retinal detachments at an early stage even though cicatricial disease is often asymmetrical. ${ }^{5}$ Data on other sequelae including less severe cicatricial disease are still being collated. The incidence of blindness of early onset from retinopathy of prematurity in surviving New Zealand infants with a birth weight $500-999 \mathrm{~g}$ was thus $7 \%$. This figure is similar to the $8 \%$ used by Phelps to produce her estimates of vision loss due to retinopathy of prematurity in the United States, ${ }^{1}$ and it is also very similar to the $7 \%$ who were found to have Kingham grade 3 or 4 retinopathy (severe cicatricial disease and blindness) in the one population based study of the incidence of retinopathy of prematurity in infants with birth weight 501 to $1000 \mathrm{~g}$ from the McMaster health region 1977-80. ${ }^{6}$

Details of neonatal care, including vitamin E usage, varied considerably between the different units throughout the country and analysis of the various risk factors for retinopathy of prematurity will be reported subsequently.

The present study is continuing for a second year and it will be important to see if the same pattern of retinopathy of prematurity with respect to birth weight and gestation is repeated. It may be that routine examination should be confined to infants of 30 weeks' gestation or less and less than $1250 \mathrm{~g}$ birth weight. To do so would have reduced the number of initial ophthalmic examinations by $34 \%$ without missing any proliferative retinopathy.

This study was supported by a project grant from the New Zealand Foundation for the Newborn.

The study could not have taken place without the participation of the following ophthalmologists: R McKay, I Elliott, J Macdiamid, J Halliwell, R Clemett, K Tarr, M Mair, P Haddad, A Ashbridge, J Mackintosh, G Martinez, P Bannister, G Moore, G Levien, $T$ Ellingham, $J$ Davison, $\mathbf{R}$ Earnshaw, and paediatricians: R Howie, D Knight, P Weston, T Gunn, S Rowley, A Trenholme, A Cull, D Bourchier, D Brabyn, M Hoby, V Richardson, T Stanley, A Kerr, A Roberts, A Farrell, C Hewitt, B Taylor, K Karthigesu, E Allen, H Lees, J Morreau, J Malcolm, R Broadbent, M Browning, L O'Leary, C Unter, D Frankish, D Somerton, D Barry, R Evans, C Moyes, L Buchanan, N Mackenzie, J Goldsmith, S Malcolm, R Mackay, P Morrison, R Pinnock, J van der Westhuyzen.

Drs JT Flynn, DL Phelps, and WA Silverman have all read the protocols for the study and made many helpful suggestions for which I am also grateful.

\section{References}

' Phelps DL. Retinopathy of prematurity: an estimate of vision loss in the United States-1979. Pediatrics 1981;67:924-6.

2 Clemett RS, Darlow BA, Hidajat RR, Tarr KH. Retinopathy of prematurity: a review of a five year period, examination techniques and recommendations for screening. Aust $N Z J$ Opthalmol 1986;14:121-5.

${ }^{3}$ Committee for the classification of retinopathy of prematurity. An international classification of retinopathy of prematurity. Pediatrics 1984;74:127-33. 
4 Alberman ED. Epidemiology of retinopathy of prematurity. In: Silverman WA, Flynn JT, eds. Contemporary issues in fetal and neonatal medicine: 2. Retinopathy of Prematurity. Boston: Blackwell Scientific, 1985: 249-66.

5 Flynn JT, Bancalari E, Bachynski BN, et al. Retinopathy of prematurity: diagnosis, severity and natural history. Ophthalmology 1987;94:620-9.

6 Saigal S, Rosenbaum P, Stoskopf B, Sinclair JC. Outcome of infants 501 to $1000 \mathrm{~g}$ birthweight delivered to residents of the McMaster health region. J Pediatr 1984;105:969-76.

Correspondence to Dr BA Darlow, Department of Paediatrics, Christchurch Hospital, Christchurch, New Zealand.

Accepted 2 March 1988

\title{
Streptokinase for aortic thrombosis
}

\author{
C R KIRK, C NI BHROLCHAIN, AND S A QURESHI \\ Department of Paediatric Cardiology, Royal Liverpool Children's Hospital, Liverpool
}

SUMmary A neonate developed complete thrombosis of the abdominal aorta after catheterisation of the umbilical artery. This was succesfully treated with an intravenous infusion of streptokinase.

Aortic thrombosis is a rare but well recognised complication of catheterisation of the umbilical artery $^{1}$ for which the accepted management is surgical thrombectomy. ${ }^{2}$ We describe a child who was successfully treated with intravenous streptokinase.

\section{Case report}

A baby boy was born at 40 weeks' gestation. $\mathrm{He}$ weighed $2340 \mathrm{~g}$ and was small for gestational age. His mother had smoked during the pregnancy. At birth his haemoglobin concentration was $259 \mathrm{~g} / 1$ and the packed cell volume was 0.75 . His blood glucose concentration subsequently dropped to $<1.0 \mathrm{mmol} / \mathrm{l}$ and he developed respiratory distress for which he required artificial ventilation. An umbilical artery catheter (Argyle size 5F. Sherwood Medical) was inserted and the tip positioned at the level of the body of the 11th thoracic vertebra. A dilutional plasma exchange transfusion was carried out and the haemoglobin concentration fell to $225 \mathrm{~g} / \mathrm{l}$ with a packed cell volume of $0 \cdot 65$. Seventy hours after its insertion the catheter had occluded and so it was removed. Twenty four hours later both the baby's legs were cold and mottled, with no pulses.

An aortogram was performed by the Seldinger technique through the right femoral artery; this showed that the abdominal aorta was completely occluded distal to the origin of the renal arteries (figure).

An intravenous bolus of $1000 \mathrm{U} / \mathrm{kg}$ of streptoki- nase was given, followed by an infusion of $1000 \stackrel{\vec{\circ}}{\circ}$ $\mathrm{U} / \mathrm{kg} / \mathrm{hour}$ into a vein on the dorsum of the hand. Eight hours later both the femoral pulses were? present on Doppler examination. After 30 hours $\vec{\infty}$ his lower limb pulses were normal and the bloodø pressure in the right arm was $87 / 54 \mathrm{~mm} \mathrm{Hg}$ and in $\frac{\overrightarrow{\mathbb{D}}}{0}$ the left leg 84/43. The streptokinase was discontinued 3 and $25 \mathrm{U} / \mathrm{kg} /$ hour of heparin given for 48 hours.

Four months later all the pulses were normal and

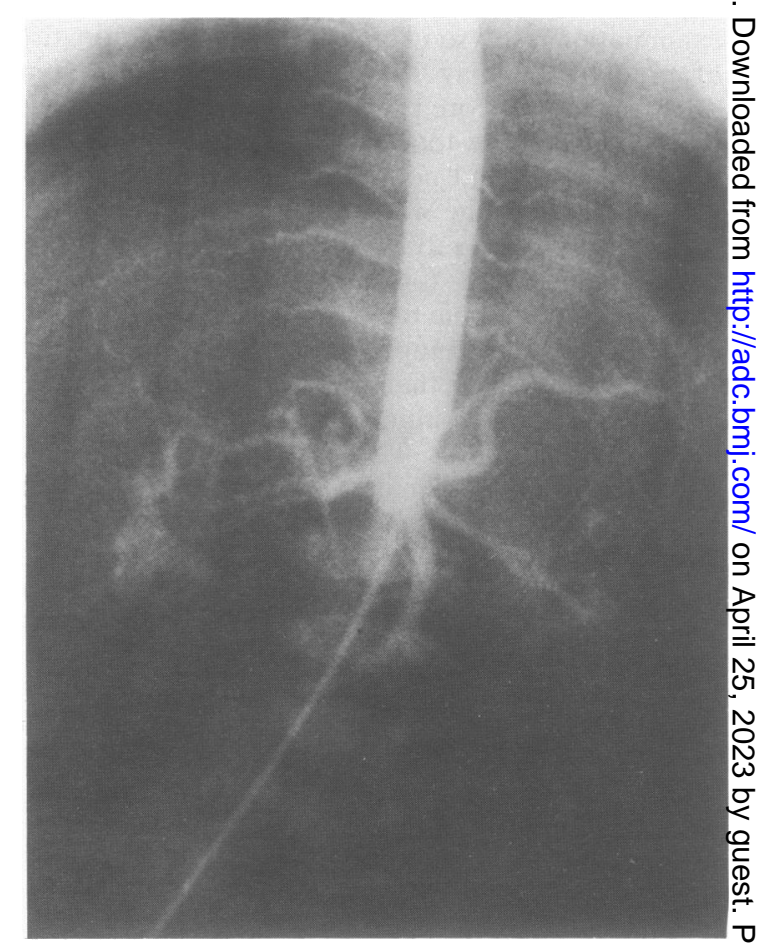

Figure Abdominal aortogram showing total occlusion of abdominal aorta below origin of renal arteries. 